\title{
Women's Attractiveness Perception of Men's Dance Movements in Relation to Self-Reported and Perceived Personality
}

\author{
Bettina Weege • Lena Barges • Michael N. Pham • \\ Todd K. Shackelford $\cdot$ Bernhard Fink
}

Published online: 4 November 2014

(C) Springer International Publishing 2014

\begin{abstract}
Recent research on women's ratings of men's dance movements indicates that women derive similar cues of male "quality" (e.g., physical strength) from movement as from faces and bodies. Whether this extends to personality assessment is yet unclear. We recorded dance movements of 80 men using 3D optical motion-capture technology and secured selfreports of men's personality standings. Dance movements were applied to a uniform, shape-standardized virtual humanoid character (avatar) and presented to women as 15-s videos for attractiveness and personality ratings. Women's ratings of dance attractiveness correlated negatively with men's selfreports and women's ratings of men's neuroticism and were positively correlated with men's self-reported extraversion and women's ratings of men's conscientiousness. Men's selfreported personality scores did not correlate with women's ratings of men's personality standings. Findings are discussed with reference to previous research and the social significance of dance movement cues and impression formation.
\end{abstract}

Keywords Dance $\cdot$ Men $\cdot$ Personality $\cdot$ Attractiveness . Stereotype

\section{Introduction}

The morphology of the face and body affects social perception (Fink and Penton-Voak 2002; Gangestad and Scheyd 2005; Grammer et al. 2003; Rhodes 2006). Dion et al. (1972)

B. Weege $\cdot$ L. Barges $\cdot$ B. Fink $(\bowtie)$

Institute of Psychology and Courant Research Centre Evolution of

Social Behavior, University of Göttingen, Kellnerweg 6,

37077 Göttingen, Germany

e-mail: bfink@gwdg.de

M. N. Pham • T. K. Shackelford

Department of Psychology, Oakland University, Rochester, MI, USA documented that people attribute desirable personality characteristics to attractive people - the "what is beautiful is good" stereotype. Although this heuristic is often regarded as bias in social perception, people sometimes use such stereotypes to identify prospective romantic partners with personality characteristics they desire (Little et al. 2006; Zhang et al. 2014).

Little et al. (2006) asked men and women to report the personality characteristics they desire in a romantic partner and then rate the attractiveness of composite facial images. Two groups of composite images were created such that blends of the most attractive faces were either based on desired or non-desired personality characteristics. A subsequent test of participants' ability to attribute personality characteristics to these composites documented that participants who desired certain personality characteristics rated faces associated with these characteristics as more attractive. Little et al. suggest that attractiveness is not an unspecific attribution but instead reflects attribution of desired personality characteristics. In short, people may provide higher attractiveness ratings when they perceive - based on facial appearancethat the target has desired personality characteristics. Zhang et al. (2014) arrived at a similar conclusion when they requested facial attractiveness ratings in the presence or absence of personality information. Faces presented with positive personality information were rated highest on attractiveness, followed by those with no personality information and faces with negative personality information. Zhang et al. concluded that personality trait manipulation influences attractiveness ratings, such as those faces reflecting desired traits are rated more attractive.

Gait cues can also affect trait ratings, particularly when making social decisions when cues of facial and body morphology are less visible. For example, Thoresen et al. (2012) presented point-light walking of motion-captured men and women to participants who were asked to rate them on major personality dimensions. As in previous studies (e.g., Ambady 
and Rosenthal 1993; Montepare and Zebrowitz-McArthur 1988), there was high agreement among raters, although there was no correlation of self-reported with perceived personality. Moreover, there were no associations of motion parameters with self-reported personality. Hence, positive relationships between self- and other assessments of personality may hold only for certain stimuli (e.g., faces; Penton-Voak et al. 2006).

In the present study, we investigated women's attractiveness and personality ratings of men's dance movements in relation to self-reported personality of male dancers. Dance is a complex form of human movement, which is observed in courtship situations in almost all human societies (see for review Hanna 1987, 2010; Hugill et al. 2010). It has been reported that male dance conveys aspects of mate quality such as physical strength (Hugill et al. 2009; McCarty et al. 2013) and sensation seeking (Hugill et al. 2011), with dances of physically strong and risk-taking men rated more attractive by women. Moreover, Fink et al. (2012) reported positive correlations of men's self-reported agreeableness and conscientiousness with women's ratings of men's dance quality. Such studies provide information about women's preferences for the dance movements of men with certain personality characteristics, but it is not known whether women's preferences are linked to the personality of the dancer, which would imply women's ability to accurately assess personality traits from dance. From an evolutionary viewpoint, such capacity would have been beneficial when assessing the personality of unfamiliar men, especially in courtship situations, in order to prevent women from male aggression and other cost-inflicting behavior. Accurate personality assessment via dance movements cannot be assumed, given the results of previous research indicating inaccurate personality assessments based on faces and gaits. Hence, inferences about dancer personality via ratings of dance attractiveness may be based on displays expressed in dance that do not match (and are not caused by) self-reported personality.

We hypothesized that women's attractiveness ratings of men's dances would correlate positively with women's ratings of men's extraversion, openness, agreeableness, and conscientiousness and would correlate negatively with ratings of men's neuroticism. Despite reports of positive relationships of women's ratings of men's dance quality with men's selfreported agreeableness and conscientiousness (Fink et al. 2012), our expectations about the relationships of men's self-reported personality with women's dance attractiveness ratings are less certain. Fink et al. had women rate men's dances on quality (good vs. bad), and quality assessments may differ from attractiveness assessments. In addition, Fink et al. reported a positive correlation of men's self-reported extraversion and a negative correlation of men's self-reported neuroticism with women's ratings of men's dance quality, but both correlations were nonsignificant, perhaps because of low statistical power $(n=48$ men). However, considering these findings together with the fact that the present study investigated a larger sample of male dancers, we hypothesized that dance attractiveness ratings would show similar relationships with self-reported personality to those with personality ratings. Finally, based on previous research reviewed above, we did not expect significant correlations between male dancers' self-reported personality and women's ratings of dancers' personality.

\section{Materials and Methods}

\section{Participants}

Eighty men aged 18 to 42 years $(M=21.61, \mathrm{SD}=4.01)$ participated. Participants were recruited from the student population at Northumbria University (UK). Participants were not professional dancers and had not experienced injuries that might affect their natural movement. Five men were not heterosexual (by self-report) and were excluded from statistical analyses. The age of the final sample of 75 heterosexual male dancers ranged from 18 to 42 years $(M=21.76, \mathrm{SD}=4.09)$.

\section{Self-Reported Personality}

Prior to dance recordings, each participant completed the 60item NEO-FFI personality inventory, which is widely used to measure the five major dimensions of adult personality (neuroticism, extraversion, openness to experience, conscientiousness, and agreeableness) (Costa and McCrae 1985, 1992). Scores for each dimension range from 0 to 4 .

\section{Dance Movements}

Dance movements of each participant were recorded using a 3D-optical motion capture system comprising 12 nearinfrared cameras (T20 Pentax lenses, VICON, Oxford, UK) and running Nexus software (VICON Nexus 1.5.1 \& 1.7.1). Following the plug-in-gait marker placement set, 39 reflective markers were affixed to participant's major joints and body parts, and movement of these markers was recorded at a rate of 200 frames per second. Participants were instructed to dance for $30 \mathrm{~s}$ in the way they would usually move in a nightclub. To control for music preferences, the same $125 \mathrm{bpm}$ repeated drum pattern was played to each participant. As described in Fink et al. (2012), dance movements were then applied to virtual, gender-neutral, form-standardized humanoid figures (avatars) using Autodesk Motionbuilder 2011 (Autodesk Inc., San Rafael, CA, USA). For dance ratings, 15-s clips were selected from the middle of each participant's dance recording and presented as $24 \mathrm{fps}, 773 \times 632$ (attractiveness) $/ 400 \times 328$ (personality) pixel-sized videos without audio. 


\section{Attractiveness Ratings}

Forty female volunteers were recruited from the student population of the University of Göttingen. On 15.4" laptop computers, they randomly presented all 80 dance videos and asked to judge each dance on attractiveness using a 7-point Likert scale anchored by $1=$ "very unattractive" and $7=$ "very attractive". After eliminating ratings provided by three self-reported non-heterosexuals, the responses of 37 heterosexual females (17 to 46 years; $M=23.96, \mathrm{SD}=4.82$ ) were included in the analysis.

\section{Personality}

A total of 227 participants (men and women) were recruited from the student population of the University of Göttingen. Fifty-one participants did not complete the ratings, and their data were therefore excluded. With respect to sexual orientation, data from a further six participants were excluded. For the present study, we considered women only. Thus, our final sample comprised 102 heterosexual women (18 to 57 years; $M=25.10 ; \mathrm{SD}=7.63)$. Using Qualtrics online survey software on 15.4" laptop computers, each participant viewed 20 randomly selected dances and was asked to assess the personality traits of the dancer. Judgments were made on five bipolar scales [with scores ranging from 1 (low on dimension) to 5 (high on dimension)] representing the five major dimensions of personality. Two pairs of traits described each dimension (one pair appearing left and the other right from the scale on the screen). Items were taken from the German version of the Ten-Item Personality Inventory (TIPI; Gosling et al. 2003; Muck et al. 2007). The order of scales was randomly arranged across participants.

\section{Results}

A one-sample Kolmogorov-Smirnov test for goodness of fit revealed no deviations from normality for men's self-reported personality scores, dance attractiveness ratings, or women's personality attributions (all $Z \mathrm{~s}<1.15$, all $p \mathrm{~s}>.15$ ). Calculated means of dance attractiveness ratings ranged from 1.86 to 4.78 $(M=3.27, \mathrm{SD}=.67)$, and there was high agreement across judges (Cronbach's alpha=.89).

Women's dance attractiveness ratings correlated negatively with men's self-reported neuroticism $(r=-.23)$ and positively with men's self-reported extraversion $(r=.22)$ (both $p \mathrm{~s}<.05$, these and subsequent $p$ s are one-tailed). Self-reported openness to experience, conscientiousness, and agreeableness of dancers did not correlate with attractiveness ratings (all $r \mathrm{~s}$ $<.13$, all $p \mathrm{~s}>.13$ ). In addition, dance attractiveness ratings correlated negatively with women's ratings of dancer neuroticism $(r=-.28, p<.01)$, positively with women's ratings of dancer conscientiousness $(r=.35, p<.01)$, but were not correlated with women's ratings of the three other dancer personality dimensions (all $r s<.11$, all $p s>.18$ ).

Men's self-reported personality scores did not correlate with women's ratings of dancer personality scores (all $r \mathrm{~s}$ $<.18$, all $p s>.07$ ). Table 1 reports inter-correlations of men's self-reports and women's ratings of personality. The following relationships were significant after Bonferroni corrections. Self-reported neuroticism correlated negatively with selfreports on extraversion, conscientiousness and agreeableness, and self-reported agreeableness.

Women's personality ratings based on men's dance movements revealed negative correlations of neuroticism with extraversion and openness. Extraversion correlated positively with openness and negatively with conscientiousness.

Finally, we did not detect any significant correlation of dancers' age and self-reported personality (all $r \mathrm{~s}<.19$, all $p \mathrm{~s}>.05$ ) and perceived personality (all $r \mathrm{~s}<.10$, all $p \mathrm{~s}>.20$ ).

\section{Discussion}

Women derive quality cues (e.g., physical strength) from men's dance movements and rate these cues as attractive (see for review Hanna 2010; Hugill et al. 2010; Fink et al. 2014). Comparably, little is known about the relationship of men's personality and women's assessments of dance attractiveness, although some research suggests that aspects of personality are conveyed through dance movements (Fink et al. 2012; Hugill et al. 2011). The current research failed to find relationships between men's self-reported personality and women's ratings of men's personality from men's dance

Table 1 Inter-correlations of men's self-reports and women's ratings of personality from dance movements

\begin{tabular}{|c|c|c|c|c|c|}
\hline & 1 & 2 & 3 & 4 & 5 \\
\hline & \multicolumn{5}{|c|}{ Self-reported personality } \\
\hline 1. Neuroticism & - & $-.45^{* *}$ & $-.21 *$ & $-.28 * *$ & $-.28^{* *}$ \\
\hline 2. Extraversion & & - & .05 & .17 & $.23^{*}$ \\
\hline 3. Openness & & & - & -.06 & $.24 *$ \\
\hline 4. Conscientiousness & & & & - & $.24 *$ \\
\hline \multirow[t]{2}{*}{ 5. Agreeableness } & & & & & - \\
\hline & \multicolumn{5}{|c|}{ Rated personality } \\
\hline 1. Neuroticism & - & $-.88^{* *}$ & $-.89 * *$ & .08 & $.25^{*}$ \\
\hline 2. Extraversion & & - & $.97 * *$ & $-.35 * *$ & .08 \\
\hline 3. Openness & & & - & $-.26^{*}$ & .17 \\
\hline 4. Conscientiousness & & & & - & $.28 * *$ \\
\hline 5. Agreeableness & & & & & - \\
\hline
\end{tabular}

Note: Correlations in italics were significant after Bonferroni correction ${ }^{*} p<.05 ; * * p<.01$ (one-tailed) 
movements. Thus, women were not able to accurately assess men's personality from dance movements - a result that corroborates research investigating relationships of self-reported personality with observer reports of personality based on gait (Thoresen et al. 2012).

Although research on personality perception from faces suggests there is a "kernel of truth" in trait impression (e.g., Berry 1990; Penton-Voak et al. 2006), accurate trait ratings may not be derivable from body movement. Thoresen et al. concluded that reliability of trait ratings in point-light walkers is driven by impressions of emotion, attractiveness, and masculinity rather than raters' abilities to accurately derive personality from motion cues. In other words, agreement in assessments of others at first impression may be driven by other cognitive mechanisms, which then produces agreement in assessments of, for example, attractiveness.

Studies using facial stimuli indicate that personality attributions are affected by raters' valuations of personality (Little et al. 2006; Zhang et al. 2014). We did not ask our female participants to report desired personality characteristics before they rated male dancers on attractiveness and personality. However, our findings on associations of perceived attractiveness and personality (conscientiousness and neuroticism) suggest that these ratings were not independent. These correlations per se do not identify causal relationships: Did women rate a dancer as attractive because they responded positively to personality cues derived from body movements, or did they rate a dancer as attractive for other reasons and-in consequence - assign "positive personality" to them?

Our finding of a negative correlation of men's self-reported neuroticism and a positive correlation of men's self-reported extraversion with women's ratings of dance attractiveness suggests that men scoring low on neuroticism and high on extraversion perform attractive dance movements. But these findings do not mean that women perceive these traits as such when being prompted for personality attributions. There may be certain male movements associated with particular personality traits, such as extraversion and neuroticism, and women perceive these movements as attractive. Alternatively, women may perceive certain dance movements as attractive and then associate positive or negative personality traits with these movements in the sense of the attractiveness stereotype (Dion et al. 1972). Finally, assessments of dance attractiveness may be produced by combination of both cognitive processes. In this context, it is interesting that dance attractiveness ratings were correlated with both men's self-reported neuroticism of women's ratings of men's neuroticism. This could indicate that men's dance movements linked to neuroticism are particularly important in women's dance attractiveness assessments. Sensitivity to movement cues that signal neuroticism suggests a mechanism of dance attractiveness assessments similar to what has been reported for assessments of face and body attractiveness assessments (Grammer et al. 2001).
Gigerenzer and Goldstein (1996) have argued that humans make inferences about uncertain aspects of the world under limited time and knowledge, following cognitive heuristics. Grammer et al. (2001) tested these "fast and frugal" algorithms by applying them to attractiveness assessments of female faces and bodies and found that "avoid the worst" best describes how humans arrive at attractiveness assessments. From an evolutionary perspective, attractiveness assessments may follow such an algorithm, which would widen the pool of potential partners. According to this logic, first impressions about the attractiveness of an individual are not made by identifying highly attractive features but by being sensitive to the worst features (Cyrus 2010). The dance attractiveness and neuroticism link, in men's self-reports and women's attributions of dance, may be produced by just such cognitive mechanisms, i.e., sensitivity to neuroticism cues in men's dance movements may be advantageous for women to attend to, given possible links of neuroticism with aggression and other cost-inflicting behavior (Hines and Saudino 2008; Moeller et al. 2010).

The present study did not investigate the biomechanical characteristics linked to personality. This is an avenue for future research. A recent study (Neave et al. 2011) reported that good dancers display larger and more variable movements in relation to bending and twisting of their head/neck and torso. These authors concluded that certain aspects of movement amplitude, speed, and variability are also important for female perceptions of male dancing ability. In the classic Heider and Simmel (1944) study, participants attributed intentional movement and goal-directed interactions to shapes, despite the absence of explicit social cues. Basic features of these objects, together with movement were sufficient to cause social attributions (Barrett et al. 2005; Dittrich and Lea 1994; Runeson and Frykholm 1983). These fundamental movement characteristics may also affect perceptions of human dance such that people who associate elements of a dance with desirable personality characteristics as a consequence rate that dance as more attractive.

Finally, one limitation of this study could be the sample size (75 male dancers). Personality relationships with physical and behavioral traits are typically low. Significant associations are typically difficult to detect in small samples, and if present, they could be due to sampling effects. Thus, the reported significant correlations of women's attractiveness judgments with men's self-reported personality and perceived personality from dances certainly require further investigation and replication in larger samples.

In conclusion, the present study documents that women's attractiveness assessments of men's dance movements are related to aspects of male personality, although men's selfreported personality did not correlate with women's ratings of men's personality. Our data indicate that neuroticism, in particular, is associated with certain dance movements, and this 
may affect women's assessments of men's dance attractiveness. Future research should test explicitly whether female psychology includes sensitivity to displays of neuroticism in an effort to avoid such men, rather than preferences for men that display high quality through dance movements. Another extension of this present study is certainly a test for possible sex differences in the accuracy of personality perception from dance, including the possibility that men perceive dance movements of other men differently than women in the context of male rivalry. We speculate that men do not necessarily share the female sensitivity to detect negative personality from dance movements but rather attend to cues signaling extraversion in believing that women admire extraverted men, though, again, this needs to be confirmed in future research.

Acknowledgments We thank Nick Neave and Kristofor McCarty for granting us access to the Newcastle Gait Lab at Northumbria University (U.K.). This work was funded by the German Science Foundation (DFG), grant numbers 1450/4-1 and FI 1450/7-1 awarded to B.F.

\section{References}

Ambady, N., \& Rosenthal, R. (1993). Half a minute - predicting teacher evaluations from thin slices of nonverbal behaviour and physical attractiveness. Journal of Personality and Social Psychology, 64, 431-441.

Barrett, H. C., Todd, P. M., Miller, G. F., \& Blythe, P. W. (2005). Accurate judgments of intention from motion cues alone: a cross-cultural study. Evolution and Human Behavior, 26, 313-331.

Berry, D. S. (1990). Taking people at face value: evidence for the kernel of truth hypothesis. Social Cognition, 8, 883-893.

Costa, P. T., \& McCrae, R. R. (1985). The NEO Personality Inventory manual. Odessa: Psychological Assessment Resources, Inc.

Costa, P. T., \& McCrae, R. R. (1992). Revised NEO Personality Inventory (NEO-PI-R) and the NEO Five-Factor Inventory (NEO-FFI): Professional manual. Odessa: Psychological Assessment Resources, Inc.

Cyrus, K. (2010). Hochattraktiv oder nur nicht unattraktiv: Was zählt bei der Partnerwahl? Vermeidung von Unattraktivität - ein negatives Attraktivitätskonzept? Digitale Dissertation, Universität Wuppertal.

Dion, K. K., Berscheid, E., \& Walster, E. (1972). What is beautiful is what is good. Journal of Personality and Social Psychology, 24, 285-290.

Dittrich, W., \& Lea, S. (1994). Visual perception of intentional motion. Perception, 23, 253-268.

Fink, B., \& Penton-Voak, I. S. (2002). Evolutionary psychology of facial attractiveness. Current Directions in Psychological Science, 11, 154-158.

Fink, B., Weege, B., Flügge, J., Röder, S., Neave, N., \& McCarty, K. (2012). Men's personality and women's perception of their dance quality. Personality and Individual Differences, 52, 232-235.

Fink, B., Weege, B., Neave, N., Ried, B., \& do Lago, O. C. (2014). Female perceptions of male body movement. In V. Weekes-Shackelford \& $\mathrm{T}$. K. Shackelford (Eds.), Evolutionary perspectives on human sexual psychology and behavior (pp. 299-324). Berlin: Springer.

Gangestad, S. W., \& Scheyd, G. J. (2005). The evolution of human physical attractiveness. Annual Review of Anthropology, 34, 523-548.

Gigerenzer, G., \& Goldstein, D. G. (1996). Reasoning the fast and frugal way: models of bounded rationality. Psychological Review, 103, 650-669.
Gosling, S. D., Rentfrow, P. J., \& Swann, W. B., Jr. (2003). A very brief measure of the big-five personality domains. Journal of Research in Personality, 37, 504-528.

Grammer, K., Fink, B., Juette, A., Ronzal, G., \& Thornhill, R. (2001). Female faces and bodies: n-dimensional feature space and attractiveness. In: G. Rhodes \& L. Zebrowitz (Eds.), Advances in Visual Cognition. Volume I: Facial Attractiveness. Ablex Publishing.

Grammer, K., Fink, B., Møller, A. P., \& Thornhill, R. (2003). Darwinian aesthetics: sexual selection and the biology of beauty. Biological Reviews, 78, 385-407.

Hanna, J. L. (1987). To dance is human: A theory of nonverbal communication. Chicago: University of Chicago Press.

Hanna, J. L. (2010). Dance and sexuality: many moves. Journal of Sex Research, 47, 212-241.

Heider, F., \& Simmel, M. (1944). An experimental study in apparent behavior. The American Journal of Psychology, 57, 243-259.

Hines, D. A., \& Saudino, K. J. (2008). Personality and intimate partner aggression in dating relationships: the role of the "big five". Aggressive Behavior, 34, 593-604.

Hugill, N., Fink, B., Neave, N., \& Seydel, H. (2009). Men's physical strength is associated with women's perceptions of their dancing ability. Personality and Individual Differences, 47, 527-530.

Hugill, N., Fink, B., \& Neave, N. (2010). The role of human body movements in mate selection. Evolutionary Psychology, 8, 66-89.

Hugill, N., Fink, B., Neave, N., Besson, A., \& Bunse, L. (2011). Women's perception of men's sensation seeking propensity from their dance movements. Personality and Individual Differences, 51, $483-487$.

Little, A. C., Burt, D. M., \& Perrett, D. I. (2006). What is good is beautiful: face preference reflects desired personality. Personality and Individual Differences, 41, 1107-1118.

McCarty, K., Hönekopp, J., Neave, N., Caplan, N., \& Fink, B. (2013). Male body movements as possible cues to physical strength: a biomechanical analysis. American Journal of Human Biology, 25, 307-312.

Moeller, S. K., Robinson, M. D., \& Bresin, K. (2010). Integrating trait and social-cognitive views of personality: neuroticism, implicit stress priming, and neuroticism-outcome relationships. Personality and Social Psychology Bulletin, 36, 677-689.

Montepare, J. M., \& Zebrowitz-McArthur, L. (1988). Impression of people created by age-related qualities of their gaits. Journal of Personality and Social Psychology, 55, 547-556.

Muck, P. M., Hell, B., \& Gosling, S. D. (2007). Construct validation of a short five-factor model instrument: a self-peer study on the German adaptation of the Ten-Item Personality Inventory (TIPI-G). European Journal of Psychological Assessment, 23, 166-175.

Neave, N., McCarty, K., Freynik, J., Caplan, N., Hönekopp, J., \& Fink, B. (2011). Male dance moves that catch a woman's eye. Biology Letters, 7, 221-24.

Penton-Voak, I. S., Pound, N., Little, A. C., \& Perrett, D. I. (2006). Personality judgments from natural and composite facial images: more evidence for a "kernel of truth" in social perception. Social Cognition, 24, 607-640.

Rhodes, G. (2006). The evolutionary psychology of facial beauty. Annual Review of Psychology, 57, 199-226.

Runeson, S., \& Frykholm, G. (1983). Kinematic specification of dynamics as an informational basis for person and action perception: expectation, gender recognition and deceptive intention. Journal of Experimental Psychology: General, 112, 580-610.

Thoresen, J. C., Vuong, Q. C., \& Atkinson, A. P. (2012). First impression: gait cues drive reliable trait judgements. Cognition, 124, 261-271.

Zhang, Y., Kong, F., Zhong, Y., \& Kou, H. (2014). Personality manipulations: do they modulate facial attractiveness ratings? Personality and Individual Differences, 70, 80-84. 